\title{
The effect of different fluoride varnishes on the release of calcium ions from hydroxyapatite discs: An ion-selective electrodes study
}

\author{
Aimi Kamarudin ${ }^{1 *}$, Paul Anderson², Robert Hill ${ }^{2}$ \\ ${ }^{1}$ Paediatric Dentistry Unit, School of Dental Sciences Universiti Sains Malaysia, Malaysia \\ ${ }^{2}$ Dental Physical Sciences Unit, Bancroft Building, Queen Mary University of London, United \\ Kingdom
}

\begin{abstract}
Introduction: Recently, various modes of fluoride varnishes have evolved, each with its own recommended concentration, potentially active ingredients, and flavour, leading to a claim of additional preventive benefits. Differences in fluoride release patterns can potentially enhance or reduce the efficacy of fluoride varnishes. Numerous clinical trials have proven its ability in preventing and arresting dental caries. This study mainly focused on the investigations of the apatite demineralisation process under the effect of different fluoride varnishes by ion-selective electrodes (ISE), in an attempt to comprehend their mechanism in anti-caries. Methods: Four different fluoride varnishes (Fluor Protector S, Duraphat, ClinPro White, MI Varnish) were used to measure their effect on the demineralisation process of the hydroxyapatite (HAP) discs in $60 \mathrm{ml} \mathrm{pH} 4.0$ acetic solutions. The HAP discs were treated with these varnishes after 4-hours demineralisation and then immersed back into the same solutions for further demineralisation to observe the effect of the varnishes. Throughout the experiment, the calcium ISE was used to monitor the rate of calcium concentration. Results: The result demonstrated that ClinPro White varnish resulted in the most significant inhibition of demineralisation and signs of probable remineralisation throughout the experiment. Other fluoride varnishes treatment showed the ability to inhibit demineralisation. However, the rate of calcium dissolution was not significantly different from different varnishes. The fact that the ClinPro White showed evidence of remineralisation might be associated with the fact that the varnish contained a source of calcium and phosphate. Conclusion: The fluoride varnishes treatment is shown to be effective in inhibiting the demineralisation of apatite regardless of the difference in fluoride concentration and potentially active ingredients incorporated in some of the fluoride varnishes.
\end{abstract}

Keywords: Demineralisation, dental caries, fluoride varnishes, ion-selective electrodes, remineralisation.

p-ISSN: 1979-0201; e-ISSN: 2549-6212; Available from: http://jurnal.unpad.ac.id/pjd/article/view/26444

DOI: $10.24198 /$ pjd.vol32no2.26444

Submission: Feb 25, 2020; Accepted: Jun 11, 2020; Published online: Jul 31, 2020

"Corresponding author: Aimi Kamarudin, Paediatric Dentistry Unit, School of Dental Sciences Universiti Sains Malaysia, Malaysia. Pusat Pengajian Sains Pergigian, Kampus Kesihatan Universiti Sains Malaysia, Kubang Kerian, Kelantan, Malaysia, 16150. Phone: +601137515053; Email: draimi@usm.my 


\section{INTRODUCTION}

A goal of modern dentistry is the non-invasive management of non-cavitated caries lesions involving a remineralisation system to repair the enamel with fluorapatite or fluorhydroxyapatite. Without doubt, fluoride supplements have contributed to a decrease in the prevalence and severity of dental caries in most industrialised countries in the past two decades. Intensive laboratory and epidemiological research on the mechanism of action in preventing caries indicates that fluoride's predominant effect is topical. ${ }^{1-3}$ Notably, the effect is maximised when it is present continuously in solution ${ }^{4}$, resulting in less mineral loss during the acid attack. ${ }^{5-7}$

The use of topically applied fluoride has increased over recent decades, and fluoridecontaining varnishes are widely used at present. Recently, a range of novel calcium-phosphatebased remineralisation delivery system have been developed for clinical application and added to products such as fluoride varnishes. Differences in fluoride release patterns can potentially enhance or reduce the efficacy of fluoride varnishes. ${ }^{8,9}$

Numerous clinical trials have proven the abilities of these fluoride varnishes in preventing and arresting dental caries. This study was focusing on the efficacy of four different fluoride varnishes in its ability in the demineralisation process of the apatite disc and whether one or any of these forms of fluoride varnishes is more effective than the other. In this study, hydroxyapatite (HAP) discs were used as tooth analogues, as described by Kosoric et al. ${ }^{10}$ This study was aimed to analyse the effect of different fluoride varnishes on the release of calcium ions from HAP discs with an ion-selective electrodes approach.

\section{METHODS}

\section{Ion Selective Electrode (ISE)}

Ion-selective electrodes (ELT8041, Nico2000 Ltd., Middlesex, UK) are solid-state electrodes that are encompassed with saturated crystalline or polyvinyl chloride that can detect ions. They are used for measuring free ion concentration in solution. Ion activity is measured by converting it into an electrical potential. The ISE measures the ion activity by using either a $\mathrm{pH}$ meter or a volumeter. The voltage is theoretically dependent on the logarithm of the ionic activity according to the Nernst Equation.

The ISE system compromises of ISE electrodes, ELITE head system, references electrode, ion $/ \mathrm{pH}$ analyser, electrochemical software for $\mathrm{ISE} / \mathrm{pH}$, two-channel interphase 2.1.22 (Chemputrix Ltd, London UK 1998).

The calcium ISE contains a PVC membrane and is saturated with organic molecules that have the ability for binding and transporting calcium ions. Inside the electrode is an internal solution with predetermined calcium chloride concentration that has been added to the potassium chloride or silver chloride solution in the internal reference system, which in the modern ISE solid state is in a solid form that is also present in the ISE.

There are three types of reference electrodes used. They are classified according to the composition of the filling solution. In this study, potassium chlorides are used with barium, calcium, fluoride and nitrous oxide.

In this study, ISE was used to measure the rate of mineral loss from HAP disc in stimulated cariogenic challenges. For each data set, the amount of calcium dissolved as a result of HAP dissolution is plotted as a function of time and calcium dissolution concentration.

\section{Calcium and reference electrode calibration}

Calcium and reference electrodes were immersed into $60 \mathrm{ml}$ of one of the calibration solutions that were prepared in Table 1. After the reading stabilised, a recording was started. $1 \mathrm{ml}$ of the acid or water was then added to dilute, and the new reading was taken. This procedure was repeated 20 times. The reading obtained from ISE is in millivolts unit that indicates the quantity of free calcium detected in the solutions as a result of the potential difference between the calcium and reference electrode measurements. This data was

Table 1. Calibration of the solutions concentration

\begin{tabular}{ccc}
\hline $\begin{array}{c}\text { Calibration solution } \\
\text { concentration } \\
(\mathrm{mM})\end{array}$ & Medium & $\begin{array}{c}\text { Amount of } \mathrm{CaCl} 2 . \\
\mathrm{H} 20 \text { added } \\
\text { (grams) }\end{array}$ \\
\hline $1(1$ litre $)$ & Deionised water & 0.1443 \\
$1(1$ litre $)$ & Acetic acid & 0.1443 \\
$1(60 \mathrm{ml})$ & Deionised water & 0.008658 \\
$1(60 \mathrm{ml})$ & Acetic acid & 0.008658 \\
\hline
\end{tabular}




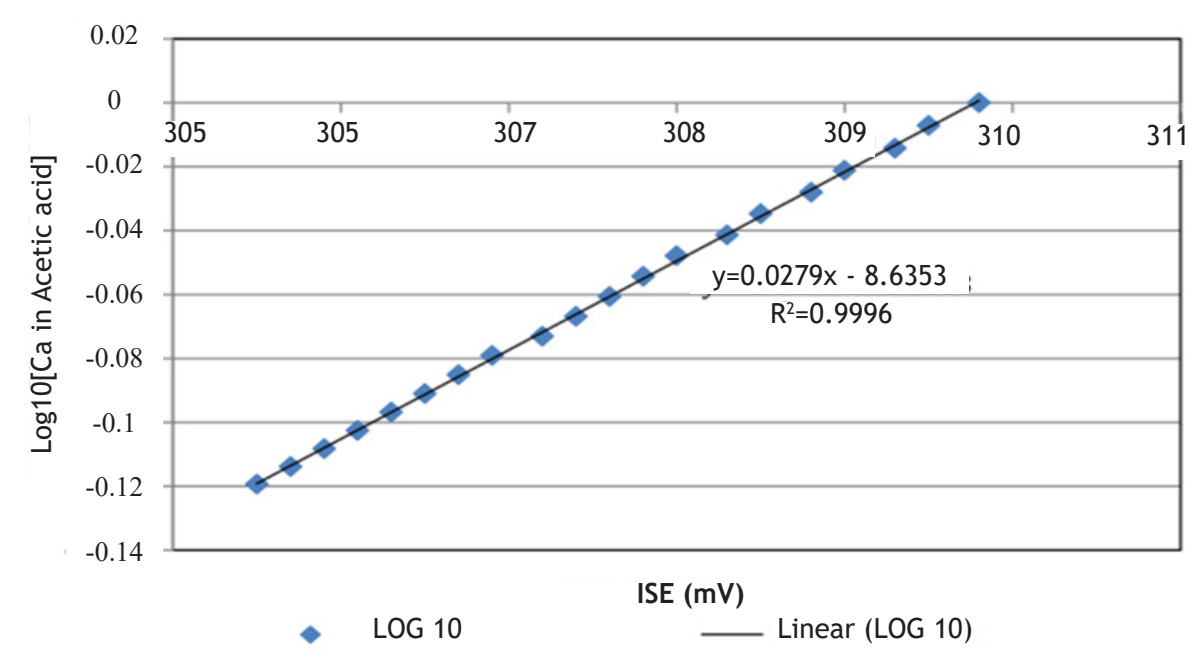

Figure 1. Calibration curve

used to plot a calibration graph, which produced a calibration equation that was then used to calculate calcium ion concentration in subsequent experiments. The calibration graph was linear, and an applicable equation was obtained to convert the ISE readings into concentration values in the following experiments, as shown in Figure 1.

\section{Varnish selection}

Four dental varnishes were selected for this study (Table 1): (1) MI Varnish with CPP-ACP containing 5\% sodium fluoride $[2.26 \%(\mathrm{w} / \mathrm{w})$ fluoride, $22.6 \mathrm{mg} / \mathrm{ml}$ fluoride or $22600 \mathrm{mg} / \mathrm{L}$ Fluoride]; (2) ClinPro White with fTCP containing $5 \%$ sodium fluoride [2.26\% $(\mathrm{w} / \mathrm{w})$ fluoride, $22.6 \mathrm{mg} / \mathrm{ml}$ fluoride or $22600 \mathrm{mg} / \mathrm{L}$ fluoride]; (3) Fluor Protector $S$ containing 1.5\% ammonium fluoride $[0.77 \%(\mathrm{w} / \mathrm{w})$ fluoride, $0.77 \mathrm{mg} / \mathrm{ml}$ fluoride or $7700 \mathrm{mg} / \mathrm{L}$ fluoride]; (4) Duraphat containing $5 \%$ sodium fluoride [2.26\% $(\mathrm{w} / \mathrm{w})$ fluoride, $22.6 \mathrm{mg} / \mathrm{ml}$ fluoride or $22600 \mathrm{mg} / \mathrm{L}$ Fluoride].

\section{HAP discs}

The specimen used in the experiment to imitate the real enamel were HAP discs with commercialised Compressed sintered HAP discs (Plasma Biotal, UK.) of $13 \mathrm{~mm}$ in diameter, $2 \mathrm{~mm}$ in thickness and $20 \%$ nominal porosity were used in each experiment. They were prepared in a windowed type disc, which can be used in the demineralisation experiments. Nail polish was used to varnish the disc, and $6 \mathrm{~mm} \times 6 \mathrm{~mm}$ square was left on the surface of the disc in order to make windowed-type discs.

\section{Demineralising solutions}

Acetic acid $(0.1 \mathrm{M} / \mathrm{L})$ was used as an acidic medium in this experiment to mimic demineralisation conditions. $6.05 \mathrm{~g}$ of pure $(100 \%)$ acetic acid was added to 1.0 litre of deionised water. This resulted in acetic acid with a pH of 2.8. Then sodium hydroxide was added gradually via a syringe to the acetic acid solutions to buffer it, resulting in acid with the $\mathrm{pH}$ value of 4.0 .

\section{Data collection procedures}

Four-compressed sintered HAP discs (Plasma Biotal, UK.) were prepared in a windowed-type disc. Nail polish was used to varnish all discs, and a $6 \mathrm{~mm} \times 6 \mathrm{~mm}$ square was left on the surface of the disc in order to make a windowed-type disc.

All four HAP discs were then coated with a single layer of one of the different fluoride varnishes, as shown in Figure 2. The amount of varnish painted on each HAP disc was determined before and after applying the varnish. The weight of each of the varnish that covered standardised area ( $6 \mathrm{~mm} \times 6 \mathrm{~mm}$ window) of the HAP disc was MI Varnish $(0.086 \mathrm{~g})$; Clinpro White $(0.082$ g); Fluor protector $\mathrm{S}(0.088 \mathrm{~g})$; Duraphat $(0.089$ g). $60 \mathrm{ml}$ of acetic acid with the $\mathrm{pH}$ value of 4.0 was poured into a breaker. The calcium and reference electrodes were then immersed into the solution while being stirred continuously using a magnetic stirrer. A few minutes were allowed for the reading to stabilise before HAP disc were added to the solution. The HAP discs were immersed into the solution for 4 hours before ISE reading was stopped, HAP discs were taken 


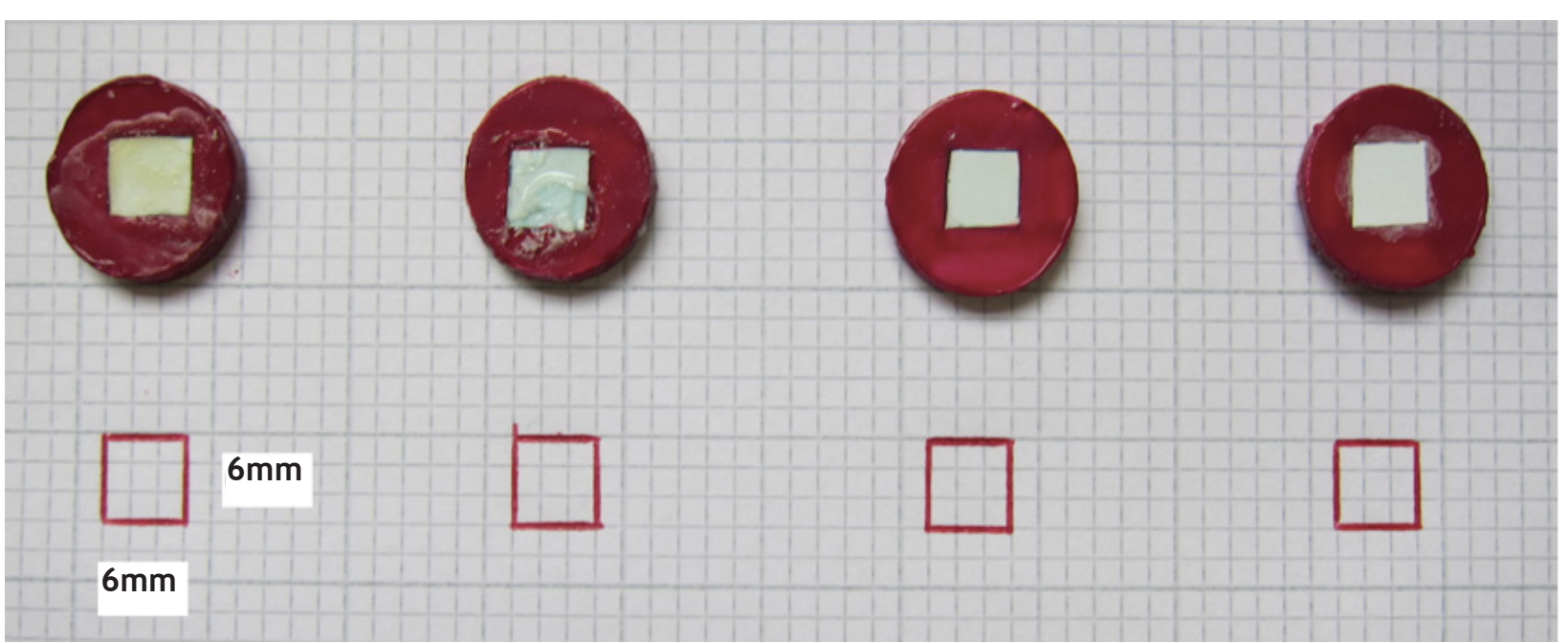

Figure 2. From left, HAP disc after treated with Duraphat, MI Varnish, Fluor protector S and Clinpro White

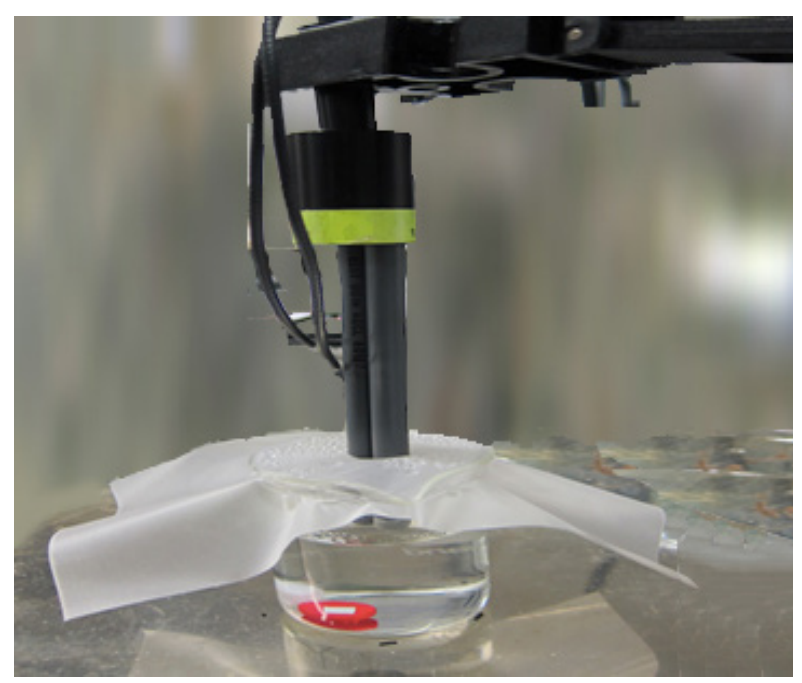

Figure 3. Experimental ISE setup

out from demineralisation solution, air-dried for 2 minutes then discs were washed with distilled water for another 2 minutes. A single, thin film of each varnish was then applied to each of the exposed window on HAP disc using the supplied or recommended applicator. The exposed surfaces with topical varnishes treated were maintained at $37^{\circ} \mathrm{C}$ for 1 minute, air dried, and the amount of varnish which had been applied was determined by reweighing the HAP disc. An attempt was made to equalise the amount of varnish on each HAP disc within about $10 \%$ by adding varnish to those with a lower weight. However, the varnish was not removed from any of the higher weight on the HAP disc once applied. All HAP discs were then immersed again in the $60 \mathrm{ml}$ acetic acid $\mathrm{pH}$ 4.0. The rate of calcium dissolution of HAP disc after being treated was determined using calcium electrode for another 4 hours. Experiments were repeated with the other topical fluorides; Clinpro White, Fluor protector S, MI Varnish, as shown in Figure 3.

\section{RESULTS}

For all cases, prior to the intervention, the mineral mass loss from the hydroxapatite discs was linear with time as previously observed. ${ }^{11}$ However, as shown from the results described in Figure $4(A-D)$, the horizontal tendency indicated that the calcium release was almost ceased after the intervention.

Figure 5 shows that there was a continuing drop in slope after 4 hours being treated with ClinPro White and calcium dissolution rate after treatment.

For each experiment, the percentage change in HAP discs was calculated for the change 



A
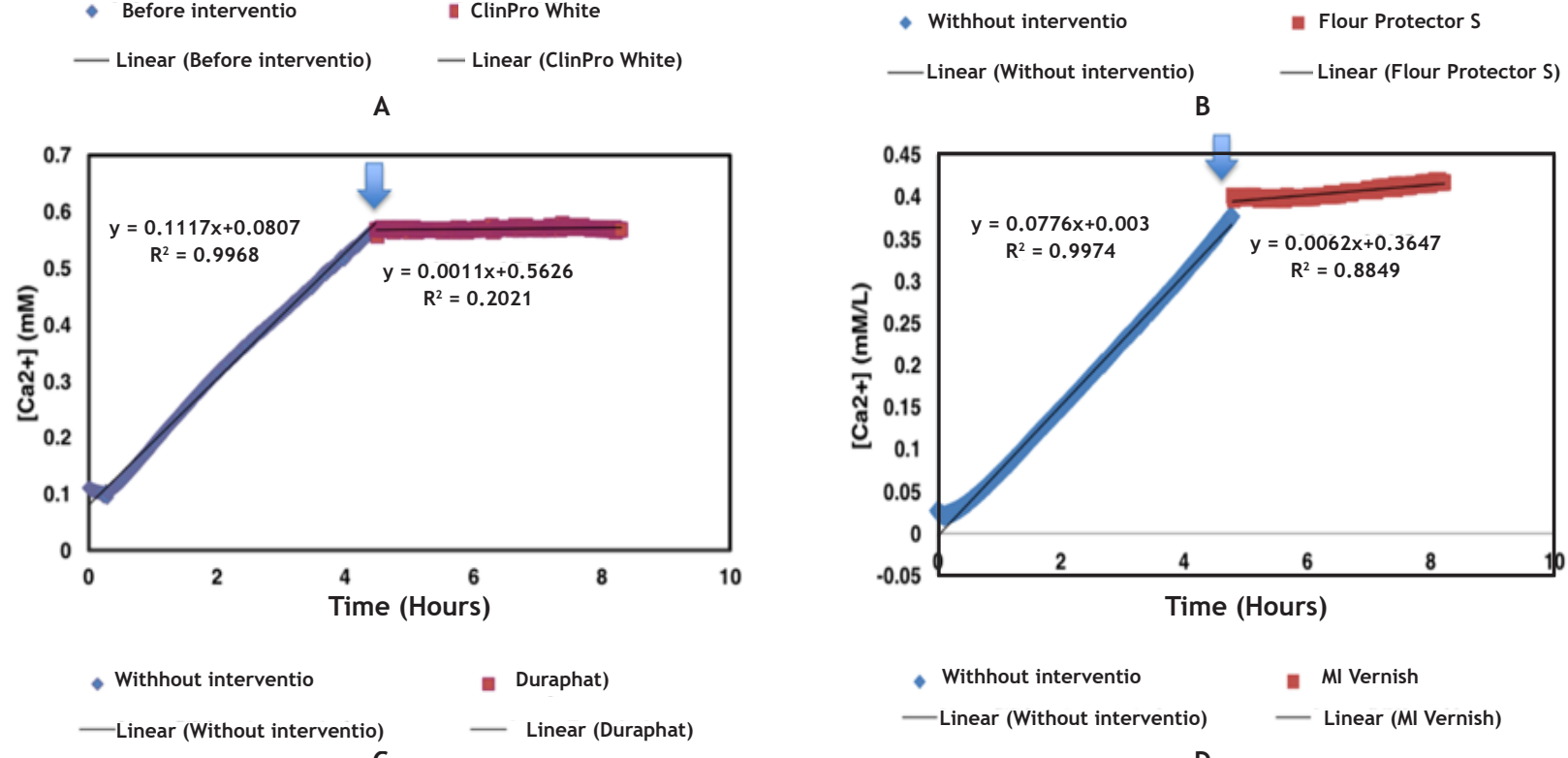

C

Figure 4. A) Windowed-type disc treated with ClinPro White varnish after 4 hours demineralisation in $60 \mathrm{ml}$ acetic acid $\mathrm{pH}$ 4.0.; B) Windowed-type disc treated with Fluor Protector $\mathrm{S}$ varnish after 4 hours demineralisation in $60 \mathrm{ml}$ acetic acid $\mathrm{pH} 4.0$. ; C) Windowed-type disc treated with MI Varnish after 4 hours demineralisation in $60 \mathrm{ml}$ acetic acid pH 4.0.; D)

Windowed-type disc treated with Duraphat varnish after 4 hours demineralisation in $60 \mathrm{ml}$ acetic acid pH 4.0 .

Table 2. Amount of calcium dissolution rate before and after intervention with fluoride varnishes

\begin{tabular}{lccc}
\hline \multicolumn{1}{c}{ Fluoride varnishes } & $\begin{array}{c}\text { Before treatment calcium } \\
\text { concentration (mmol/L) }\end{array}$ & $\begin{array}{c}\text { After treatment calcium } \\
\text { concentration (mmol/L) }\end{array}$ & $\begin{array}{c}\text { Percentage inhibition } \\
(\%)\end{array}$ \\
\hline Clinpro White & 0.0885 & -0.0052 & $0(100)$ \\
Duraphat & 0.1117 & 0.0011 & $0.98(99.02)$ \\
Fluor protector S & 0.1514 & 0.0191 & $12.61(87.39)$ \\
MI Varnish & 0.0776 & 0.0062 & $7.9(92.1)$ \\
\hline
\end{tabular}

in calcium dissolution following the intervention. The amount of calcium dissolution rate before and after intervention with fluoride varnishes is expressed as $\mathrm{mmol} / \mathrm{L}$. Table 2 shows the amount of calcium dissolution rate before and after intervention with fluoride varnishes.

Percentage of inhibition of calcium dissolution after intervention with fluoride varnishes is shown in Figure 6. ClinPro White has the highest percentage of inhibition of calcium dissolution on HAP disc within 4 hours after the intervention. The hydroxapatite discs treated with Fluor protector $\mathrm{S}$ has the lowest ability in inhibiting calcium dissolution in demineralisation condition.

The calcium dissolution rate was plotted against the log of fluoride. The log fluoride content was calculated from the change of the sodium fluoride in each of fluoride varnishes as stated from the manufacture (ppm) as shown in Figure 7. 


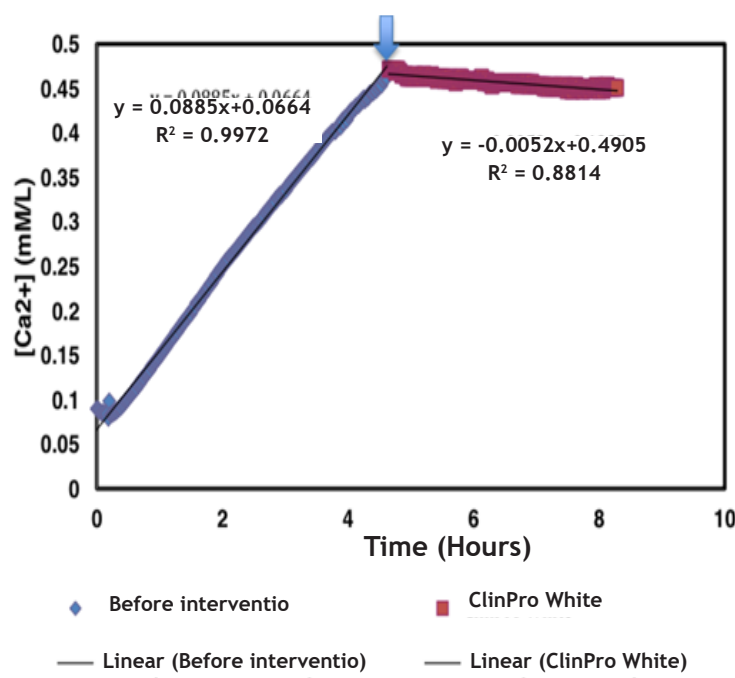

Figure 5. Windowed-type disc treated with ClinPro White varnish after 4 hours demineralisation in $60 \mathrm{ml}$ acetic acid with the $\mathrm{pH}$ value of 4.0 .

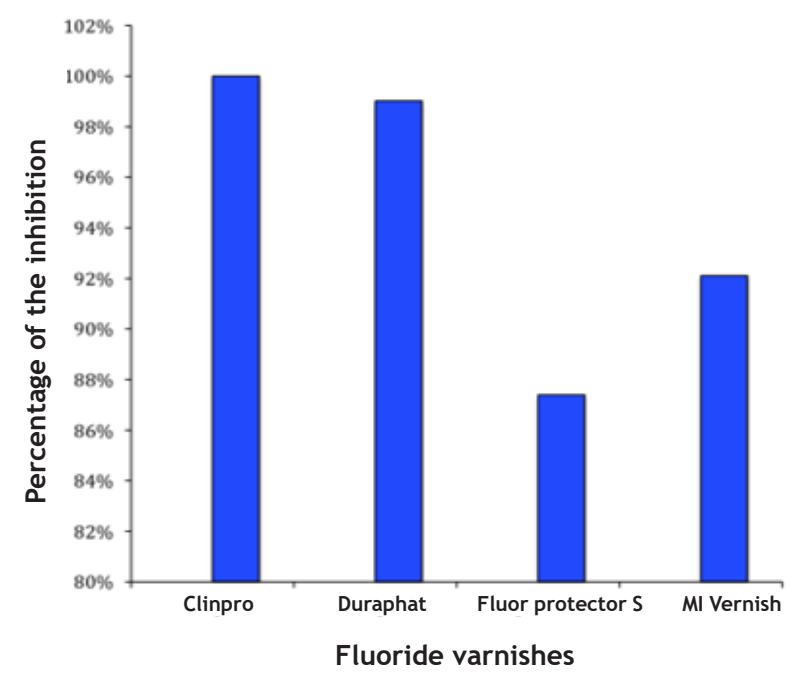

Figure 6. Percentage of the inhibition of calcium dissolution against different fluoride varnishes

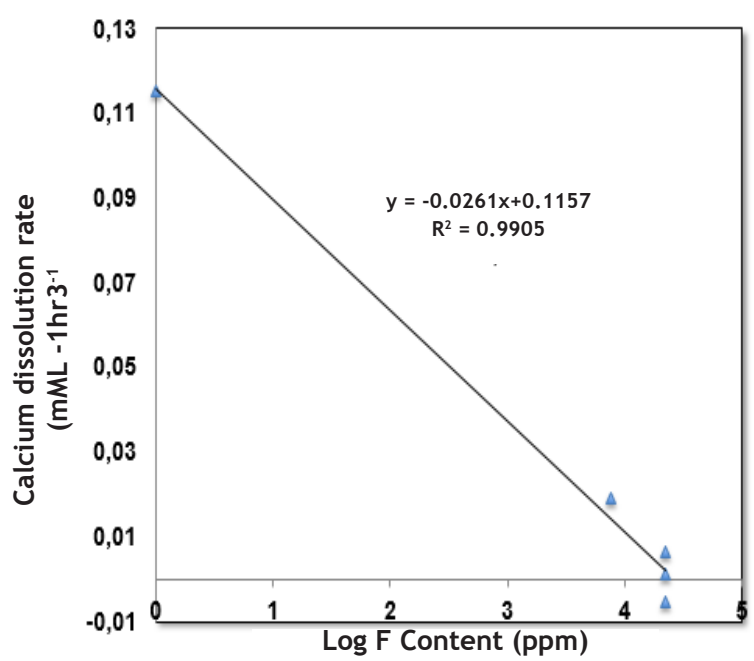

Figure 7. Calcium dissolution rate against Log of the fluoride content
There was an initial and rapid decrease from the control until HAP discs were treated with a range of fluoride varnishes. Fluor Protector $\mathrm{S}$ has the highest calcium dissolution rate compared to other fluoride varnishes. ClinPro White varnish has shown the lowest calcium dissolution after treatment.

\section{DISCUSSION}

The use of professional topical fluoride that provides fluoride to the exposed surface dentition, at elevated concentrations, for local protective effect has increased over recent decades. Recently, various modes of fluoride varnishes have evolved, each with its own recommended concentration, potentially active ingredients, and flavour, leading to a claim of additional preventive benefit. Differences in the fluoride release pattern can potentially enhance or reduce the efficacy of fluoride varnishes. ${ }^{12,13}$ Numerous clinical trials have proven its ability in preventing and arresting dental caries. The main focus of this study is the efficacy of four different fluoride varnishes in their ability in demineralisation process of the apatite discs, and whether one of these forms of fluoride varnishes is more effective than the other. ${ }^{14}$

Artificial HAP discs have previously been used as a model system or analogues for natural enamel because of their thickness, homogeneity and composition. ${ }^{10,15}$ Furthermore, numerous studies have used acetic acid $(\mathrm{pH}=4.0)$ as a demineralising solution to mimic caries-like conditions in vitro. ${ }^{11,15,16}$

All the slope and rate values of the experiment were gathered into a table to showcase the effects of all the fluoride varnishes. Four hours control demineralisation for every topical varnish there are minor discrepancies. This condition might be explained due to the manufacturer's error. Every disc was not the same to each other. New HAP discs were used for each experiment, which may differ slightly in chemical structure. Furthermore, new batches of demineralising solution were used for each series of experiments. The amount of calcium dissolution rate release from time slightly differs between ClinPro White, Fluor protector S, Duraphat and MI Varnish. However, as is shown from the results, the 
horizontal tendency indicates that the calcium release was almost ceased after the intervention. These findings identified that continuous ISE timedependent $\left[\mathrm{Ca}^{2+}\right]$ release studies demonstrate that dissolution inhibition by different fluoride varnishes was rapid. The findings also support the theory of 'ceiling effect' that application of high fluoride concentration resulted in the tremendous inhibition in demineralisation, which might be attributed to the formation of $\mathrm{CaF}_{2}$ covering the HAP disc surfaces and acted as the reservoir of fluoride for the FAP establishment later on. ${ }^{6}$ Due to the thick formation of $\mathrm{CaF}_{2}$ covering the HAP disc surfaces, the thick barrier will eventually inhibit calcium dissolution rate release. However, ISE system can only detect the dissolved ions in the aqueous phase, the release of calcium ions could be recorded, whereby the deposition like $\mathrm{CaF}_{2}$ could not be documented. On the other hand, the result was in line with the previous study that stated fluoride also could change the rate of dissolution without changing the hydroxyapatite mineral solubility.

Interestingly, in HAP disc treated with ClinPro White appear to have signs of remineralisation. Additional calcium and inorganic phosphate into fluoride varnish may lead to inhibiting demineralisation and further remineralisation on HAP disc. There was a continuing drop in slope after 4 hours being treated with ClinPro White and calcium dissolution rate after treatment was $(-0.0052)$. This finding supports the hypothesis that apart from inhibiting demineralisation, fluoride varnishes (ClinPro White) also at the same time might demonstrate signs of remineralisation within four hours. Fluoride varnish has a short life span in the oral environment as it is removed by the action of the cheeks and tongue, salivary flow, mastication and oral hygiene procedure. Therefore, varnishes should release their ions in a relatively short period before the varnish is lost. It has been estimated that varnishes only remain in situ for up to 24 hours. The combined use of calcium and fluoride, in particular ClinPro White, has shown signs of remineralisation within 4 hours under caries-like demineralising conditions, so this new varnish may have the potential to improve caries prevention further.

In terms of the ability in inhibiting calcium rate dissolution in demineralisation condition,
ClinPro White has the best outcome $(100 \%)$ followed by Duraphat (99\%), MI Varnish (92\%) and Fluor Protector S (87\%). These findings are consistent with previous research that some of these secondary ingredients may affect the fluoride ion release of the product. ${ }^{17,18}$ Fluoride release and subsequent formation of calcium fluoride are thought to be an essential part of the mechanism of action of fluoride varnishes to prevent demineralisation. Moreover, differences in fluoride release patterns can potentially enhance or diminish the efficacy of fluoride varnishes. It is also apparent that this finding agreed with the observation of Seppa ${ }^{19}$ who reported that the higher the fluoride concentration, the greater the fluoride uptake by enamel. On the other note, Fluor Protector $\mathrm{S}$ has the lowest concentration of fluoride ( $1.5 \%$ ammonium fluoride) compared to other dental varnishes and is likely to have the lowest rate of dissolution inhibition. More research is therefore needed to understand better that it is essential that the addition of calcium and phosphate ions does not reduce the availability of fluoride ions as it is the fluoride that has been shown in clinical trials to provide the caries preventive efficacy of the varnish. ${ }^{20}$ For future studies, the fluoride and phosphate concentration in the demineralising solution after the application of different fluoride varnishes should be determined. However, we need to be cautious about these findings, as this study does not represent the exact and real conditions as in oral conditions.

\section{CONCLUSION}

The fluoride varnishes treatment was shown to be effective in inhibiting the demineralisation of apatite regardless of the difference in fluoride concentration and potentially active ingredients incorporated in some of the fluoride varnishes. Amongst four different fluoride varnishes in this study, ClinPro White has shown possible signs of remineralisation under caries like demineralising conditions within 4 hours duration. Sodium fluoride and ammonium fluoride decreases the rate of HAP disc dissolution under caries-like demineralising conditions. Continuous ISE time-dependent $\left[\mathrm{Ca}_{2+}\right]$ release studies demonstrate that dissolution inhibition by different fluoride varnishes is rapid. 


\section{REFERENCES}

1. Featherstone JD. Prevention and reversal of dental caries: role of low level fluoride. Community Dent Oral Epidemiol. 1999;27(1):31-40. DOI: 10.1111/j.16000528.1999.tb01989.x

2. Hellwig E, Lennon AM. Systemic versus topical fluoride. Caries Res. 2004;38(3):258-62. DOI: 10.1159/000077764

3. Featherstone JDB. Caries prevention and reversal based on the caries balance. Pediatr Dent. 2006;28(2):128-32; discussion 192-8.

4. White DJ, Nelson DG, Faller RV. Mode of action of fluoride: application of new techniques and test methods to the examination of the mechanism of action of topical fluoride. Adv Dent Res. 1994;8(2):166-74. DOI: 10.1177/08959374940080020601

5. Duggal MS, Toumba KJ, Amaechi BT, Kowash $M B$, Higham SM. Enamel demineralization in situ with various frequencies of carbohydrate consumption with and without fluoride toothpaste. J Dent Res. 2001;80(8):1721-4. DOI: $10.1177 / 00220345010800080801$

6. Mohammed NR, Kent NW, Lynch RJM, Karpukhina N, Hill R, Anderson P. Effects of fluoride on in vitro enamel demineralization analyzed by (1)(9)F MAS-NMR. Caries Res. 2013;47(5):421-8. DOI: 10.1159/000350171

7. Issa Al, Preston KP, Preston AJ, Toumba KJ, Duggal MS. A study investigating the formation of artificial sub-surface enamel caries-like lesions in deciduous and permanent teeth in the presence and absence of fluoride. Arch Oral Biol. 2003;48(8):567-71. DOI: 10.1016/ s0003-9969(03)00095-5

8. Jablonowski BL, Bartoloni JA, Hensley DM, Vandewalle KS. Fluoride release from newly marketed fluoride varnishes. Quintessence Int. 2012;43(3):221-8.

9. Ritwik P, Aubel JD, Xu X, Fan Y, Hagan J. Evaluation of short-term fluoride release from fluoride varnishes. J Clin Pediatr Dent. 2012;36(3):275-8. DOI: 10.17796/ jcpd.36.3.q304488478w52334

10. Kosoric J, Hector MP, Anderson P. The influence of proteins on demineralization kinetics of hydroxyapatite aggregates. J Biomed Mater Res A. 2010;94(3):972-7. DOI: 10.1002/ jbm.a.32759

11. Bollet-Quivogne FR, Anderson P, Dowker SEP, Elliott JC. Demineralisation of permeable hydroxyapatite with alternating water and acidic buffer: scanning microradiographic study of effect of switching period. Caries Res. 2007;41(2):152-60. DOI: 10.1159/000098050

12. Rirattanapong $P$, Vongsavan $K$, Saengsirinavin C, Pornmahala T. Effect of fluoride varnishes containing tri-calcium phosphate sources on remineralization of initial primary enamel lesions. Southeast Asian J Trop Med Public Health. 2014;45(2):499-504.

13. Rirattanapong $P$, Vongsavan $K$, Saengsirinavin C, Pornmahala T. Effect of fluoride varnishes containing different calcium phosphate sources on mineralization of initial primary enamel lesions. Southeast Asian J Trop Med Public Health. 2014;45(6):1503-10.

14. Cochrane NJ, Cai F, Huq NL, Burrow MF, Reynolds EC. New approaches to enhanced remineralization of tooth enamel. J Dent Res. 2010;89(11):1187-97. DOI: 10.1177/0022034510376046

15. Elliott JC, Bollet-Quivogne FRG, Anderson P, Dowker SEP, Wilson RM, Davis GR. Acidic demineralization of apatitesstudied byscanning X-ray microradiography and microtomography. Mineral Mag. 2005;69(5):643-52. DOI: 10.1180/0026461056950276

16. Anderson P, Bollet-Quivogne FRG, Dowker SEP, Elliott JC. Demineralization in enamel and hydroxyapatite aggregates at increasing ionic strengths. Arch Oral Biol. 2004;49(3):199-207. DOI: $10.1016 / j$.archoralbio.2003.10.001

17. Retief DH, Sorvas PG, Bradley EL, Taylor RE, Walker AR. In vitro fluoride uptake, distribution and retention by human enamel after 1 - and 24-hour application of various topical fluoride agents. J Dent Res. 1980;59(3):573-82. DOI: 10.1177/00220345800590030401

18. Acuna V, von Beetzen $M$, Caracatsanis $M$, Sundstrom F. In vitro fluoride uptake by enamel and dentin. A comparative study of two varnishes. Acta Odontol Scand. 1990;48(2):8992. DOI: $10.3109 / 00016359009005862$

19. Seppa L. Effects of a sodium fluoride solution and a varnish with different fluoride concentrations on enamel remineralization in vitro. Scand J Dent Res. 1988;96(4):304-9. 
DOI: $10.1111 / j .1600-0722.1988 . t b 01560 . x$

20. Schemehorn BR, Wood GD, McHale W, Winston $A E$. Comparison of fluoride uptake into tooth enamel from two fluoride varnishes containing different calcium phosphate sources. J Clin Dent. 2011;22(2):51-4. 